\title{
SEISMIC RISK ASSESSMENT OF ALGERIAN BUILDINGS IN URBAN AREA
}

\author{
Fatima Zohra BABA HAMED ${ }^{\mathrm{a}}$, Driss Djaouad RAHAL ${ }^{\mathrm{a}}$, Farid RAHAL ${ }^{\mathrm{b}}$ \\ ${ }^{a}$ Department of Civil Engineering, University of Sciences and Technology Mohamed Boudiaf, \\ BP 1505 E1 M'Naouer, 31000 Oran, Algeria \\ ${ }^{b}$ Department of Architecture, University of Sciences and Technology Mohamed Boudiaf, \\ BP 1505 E1 M’Naouer, 31000 Oran, Algeria
}

Received 12 Jan. 2011; accepted 25 Aug. 2011

\begin{abstract}
The recent earthquakes in Algeria have caused significant human and economic losses. The frequent occurrence of damaging earthquakes clearly demonstrates the urgent need of study on seismic risk assessment methods of buildings to effectively reduce the impact of earthquake in Algerian cities.

This article contributes to the development and the application of a seismic risk method, appropriate to Algerian building specificities. This method considers five damage levels, defined accordingly to macroseismic intensity and the seismic quality of the building by means of a vulnerability index.

The present paper summarises the development of a tool to integrate seismic hazard and structural information and support the decision making process in identification of seismic risk. This tool could be used in the inspection of buildings and the optimal prioritisation of strengthening and preventives remedial actions that are necessary prior to a major earthquake event.
\end{abstract}

Keywords: seismic risk; seismic hazard; vulnerability index; building inventory; damage.

Reference to this paper should be made as follows: Baba Hamed, F. Z.; Rahal, D. D.; Rahal, F. 2013. Seismic risk assessment of Algerian buildings in urban area, Journal of Civil Engineering and Management 19(3): 348-363.

\section{Introduction}

Most of the losses from earthquakes are caused by the high vulnerability of the housing stock. In urban areas, this vulnerability, combined with a high concentration of buildings, can lead to a high seismic risk. The seismic risk assessment requires first the evaluation of seismic vulnerability.

In general terms, seismic risk loss could be estimated as follows (Coburn, Spence 2002):

$$
\text { Risk }=\text { hazard } \times \text { vulnerability }
$$

where the hazard is the probability of a seismic intensity for a specified period of time.

There are two general approaches for determining ground motion, deterministic models and probabilistic models (Giovinazzi 2005). One or other of these approaches can be used for a given site.

The deterministic analysis is defined as the determining of the characteristics of the maximum possible earthquake at a given site (macroseismic intensity, parameters of ground motion, response spectrum). This approach uses historical and geological data to generate scenarios.
The probabilistic analysis is defined as the determination of probabilities exceeded or not exceeded in a given site during a period (e.g. annual probabilities), the characteristic values of the intensity of an earthquake (or macroseismic intensity of ground motion parameters: acceleration, velocity, and displacement).

The seismic vulnerability of a structure can be described as its susceptibility to damage by ground shaking of a given intensity. The aim of a vulnerability assessment is to obtain the probability of a given level of damage to a given building type due to a scenario earthquake (Calvi et al. 2006).

Diverse methods were adopted to evaluate the seismic vulnerability of buildings at the territorial level based on:

(1) Damage probability of matrices (Braga, Liberatore 1982). These methods are based on statistics of damage during past earthquakes;

(2) The expert judgment (ATC-13 1985; ATC-21 1988; McCormack, Rad 1997; Benedetti, Petrini 1984). From the expert consultation, we derive the matrices of probable damage for different classes of buildings;

Corresponding author. Fatima Zohra Baba Hamed

E-mail: fatimazohra_r@yahoo.com 
(3) Analytical methods (Chopra, Goel 1999; FEMA 2002). These models should allow to analyze a large number of buildings in a short period of time. This leads to the introduction of simple models that require the introduction of only few parameters.

At present the most recent trend for the assessment of vulnerability to seismic risk analysis using the method of analysis capacity. A very detailed presentation of methods of analysis of vulnerability with their criticism is made in the work of Rossetto and Elnashai (2003). With the advances of information technology, it is now possible to overcome the difficulties in data collection and analysis and to significantly improve the efficiency and accessibility of loss estimation techniques (Bendimerad 2001).

Many programs for estimating losses from earthquakes are based on the damage prediction. Most of them use GIS software and algorithms to calculate and map the damage according to specific scenarios. These general programs include: HAZUS (1999), RADIUS (1999), and RISK-UE (2004).

HAZUS is a complex method of estimation of seismic damage, presented in the form of software. The program is organized into several interdependent modules, allowing the insertion of new additional data or new calculation modules. All the information and the results are presented in a cartographic form, integrated in a GIS. HAZ-TAIWAN programs, Selena and HAZTURK follows a similar approach to that used in HAZUS (Yeh et al. 2006; Molina, Lindholm 2005; Molina et al. 2008; Karaman et al. 2008; Korkmaz 2009). But minor changes in the analytical models and parameters have been carried out to meet the particular environment and engineering practices in different regions.

RADIUS is the implementation of a program initiated by the International Decade for Natural Disaster Reduction (1990-2000), under the aegis of the United Nations to contribute to the reduction of seismic risk in urban areas, particularly in developing countries. The main objectives of RADIUS are: the realization of the damage scenarios and action plans against earthquake risk in selected cities; the development of a tool for seismic risk management, applicable everywhere; the comparison of urban seismic risk around the world; and, finally, the promotion of information exchange for reducing the risk at the city level.

RISK-UE is a study to develop seismic risk scenarios applied to different European cities (Mouroux et al. 2004; Mouroux, Le Brun 2006). The project consists to develop a model for estimating earthquake damage suited to the European context. The study is structured in four main steps: an inventory of issues, the development of methodology for the study of earthquake scenarios, the application to some cities and analysis of the results.
In recent years, remote sensing techniques such as light detection and ranging, hyperspectral and multispectral methods, QuickBird and Landsat imagery, aerial photography and methods radar (InSAR), are used in order to extract the types of construction and the geometric characteristics exactly and verify the print and height (Korkmaz, Kutay 2010; André et al. 2001).

Algeria is located in a seismic zone with moderate to very high buildings have a high vulnerability, therefore, a high probability of being damaged, even in the case of an earthquake whose intensity is not excessive. The purpose of this paper is to develop a simple model to evaluate the seismic risk of existing buildings at the regional level. A good assessment of seismic risk in existing buildings is a necessary action to identify the most critical areas and assess the strengthening priorities of buildings.

This study applied the method of the vulnerability index to assess the seismic risk of buildings in Algerians urban areas.

\section{Index vulnerability assessment processes}

\subsection{Procedure for rapid visual seismic evaluation (FEMA-154)}

The rapid visual screening procedure was developed by the Federal Emergency Management Agency (FEMA) to identify the primary lateral resistance systems and seismic deficiencies in buildings. After a quick visual assessment of a building, it is assigned a rating-based structural (BSH, basic structural hazard). In the FEMA 154-2002 BSH rating is the probability of collapse of a building type for the maximum probable earthquake. It is calculated by the negative base 10 logarithm of this probability:

$$
\mathrm{BSH}=-\log 10 \text { (Pcollapse given the MCE). }
$$

The basic structural rating is then modified by the addition or subtraction of modifying factors of performance SM established according to the deficiencies observed for different classes of building. The final score $S$ is the measure of the probability of collapse of the building in the study:

$$
S=\mathrm{BSH} \pm \mathrm{SMs} .
$$

The structural characteristics considered by SM modifying factors are:

- Building height: medium or high;

- Irregularities: horizontal or vertical;

- Year of Design and Construction: pre- and postcode reference year;

- Soil types couterLire phontiquement.

In this approach, the basic structural rating BSH depends on the area of seismic hazard and vulnerability related to the maintenance of the buildings in case of an earthquake (typology and structural defects). 


\subsection{Score assignment procedure in Canada}

In Canada, the scoring method is described in the Manual for Screening of Buildings for Seismic Investigation (NRC-IRC 1992). Based on the ATC-21 (1988) report of the USA, it is suitable for seismic and construction practices in Canada.

Scores consider non structural hazards, the importance of building and occupational category. The final scores are structural index, SI; non-structural index, INS; and the priority index seismic, SPI, the latter being the sum of the two previous indices. The final structural index SI is obtained by multiplying the basic structural rating $\mathrm{C}$ by ratings $\mathrm{A}, \mathrm{B}, \mathrm{D}$, and $\mathrm{E}$, respectively, representing: seismicity, soil conditions, the irregularities of the building, and the importance of the building:

$$
\mathrm{SI}=\mathrm{A} \times \mathrm{B} \times \mathrm{C} \times \mathrm{D} \times \mathrm{E} .
$$

The non-structural index is the product of dimensions representing the conditions of soil $\mathrm{B}$, the importance of building $\mathrm{E}$ and the dangers related to non structural $\mathrm{F}$ :

$$
\mathrm{NSI}=\mathrm{B} \times \mathrm{E} \times \mathrm{F} .
$$

\subsection{Index vulnerability method of CNR-GNDT}

A detailed process to qualify the seismic vulnerability of buildings was established by the Gruppo Nazionale per la Difesa dai Terremoti from the Italian Consiglio Nazionale delle Ricerche (CNR-GNDT).

GNDT method is widely used now, made it possible to identify thousands of buildings throughout Italy (Augusti, Ciampoli 2000). It usually has two levels of evaluation using a standard form for information and a detailed form for buildings. Contrary to previous methods, the detailed form allows to consider the various probable failure modes and construction details for masonry buildings and reinforced concrete (RC) buildings.

The vulnerability index of masonry buildings is calculated for 11 factors described in Table 1. There are four classes of masonry buildings: A, B, C, and D. Category A is the least vulnerable, while Class D is the most vulnerable. For each parameter and each class is rated $V_{i}$ whose contribution is weighted by a factor of $\mathrm{W}_{\mathrm{i}}$. The allocation to each class is made by instructions developed by GNDT (1994).

Typology and organization of the vertical structure describes the characteristics of the structural system of the building.

Nature of the structural system evaluates the quality of the resisting system with criteria depending on: the materials property, the type of masonry (suck masonry, etc.) and the connections.
Conventional resistance evaluates the ratio between the acting base shear and the resistant baseshear of the structure.

Location and type of foundation evaluates, qualitatively through visual inspection, the influence of the terrain and the foundation in seismic behavior.

Type of slabs evaluates the rigidity of the slabs and their connections to the vertical resisting elements.

Planimetry: compactness accounts for mass and rigidity distribution of resisting elements, as well as the plan shape of the building.

Regularity considers specific criteria to evaluate the vertical configuration as the accounts for vertical irregularity of the building by the description of vertical setbacks, the factors that quantify mass variations between successive levels the variation of the resisting system in height.

Maximum distance between walls takes into account the distance between two different orthogonal resistant walls.

Roofing describes the type of roofing.

Details consider the nature of the non structural elements; elements that may or may not collapse partialy or totally depending on the connection quality to the resisting elements in the structure.

Physical condition is a subjective parameter, qualified through a simple visual inspection that may penalize the presence of imperfections in the structure as well as possible irregularities identified as results of a poor construction process. Additionally, imperfections or damage in foundations may be detected.

The index of vulnerability of masonry buildings is defined by the following formula (GNDT 1994):

$$
I=\sum_{\mathrm{i}=1}^{11} \mathrm{v}_{\mathrm{i}} \times \mathrm{w}_{\mathrm{i}} .
$$

The vulnerability assessment of RC buildings is treated taking into account 11 parameters (Table 2). Each parameter defines a particular factor that is considered critical to the seismic performance.

There are three classes of RC buildings: A, B, and C. Class A is the least vulnerable, while the $\mathrm{C}$ is most vulnerable. The allocation to each class is made by GNDT (1986) and instructions developed by CNR (1993).

Diaphragms identify horizontal resistance elements that act to transfer lateral forces between vertical resisting elements. This parameter evaluates the rigidity of the slabs and their connections to the vertical resisting elements.

Connectivity between elements evaluates the connections in lateral load transfer and resistance of the structural system of beam-column or slab-column.

Low Ductility Structural Members evaluate the presence of low ductility structural members. 
Table 1. Table of parameters, classes and weights considered by GNDT for masonry buildings

\begin{tabular}{|c|c|c|c|c|c|c|}
\hline \multirow[b]{2}{*}{ Vulnerability factors } & \multicolumn{4}{|c|}{ Class score } & \multicolumn{2}{|c|}{ Weight } \\
\hline & A & $\mathrm{B}$ & $\mathrm{C}$ & $\mathrm{D}$ & GNDT & Modifier weight \\
\hline 1. Typology and organization of the vertical structure & 0 & 5 & 20 & 45 & 1.50 & 1 \\
\hline 2. Nature of the structural system & 0 & 5 & 25 & 45 & 0.25 & 0.5 \\
\hline 3. Conventional resistance & 0 & 5 & 25 & 45 & 1.50 & 1.75 \\
\hline 4. Location and type of foundation & 0 & 5 & 25 & 45 & 1.50 & 1.5 \\
\hline 5. Type of slabs & 0 & 5 & 15 & 45 & $0.5<\mathrm{k}<1$ & 1 \\
\hline 6. Planimetry: compactness & 0 & 5 & 25 & 45 & 0.75 & 0.75 \\
\hline 7. Regularity in elevation & 0 & 5 & 25 & 45 & $0.75<\mathrm{k}<1$ & 0.75 \\
\hline 8. Maximum distance between walls & 0 & 5 & 25 & 45 & 0.25 & 0.25 \\
\hline 9. Roofing & 0 & 15 & 25 & 45 & VAR & 0.25 \\
\hline 10. Details & 0 & 0 & 25 & 45 & 0.25 & 0.25 \\
\hline 11. Physical condition & 0 & 5 & 25 & 45 & 1 & 1 \\
\hline
\end{tabular}

The index of vulnerability of RC buildings is defined by the following formula (GNDT 1986):

$$
I=12.5+2.5 \sum_{\mathrm{i}=1}^{11} \mathrm{v}_{\mathrm{i}} \times \mathrm{w}_{\mathrm{i}} .
$$

\section{Seismic risk in northern Algeria}

Northern Algeria is located in the eastern part of the Ibero-Maghrebian region, in the westernmost Mediterranean area. This region is characterized by a complex seismotectonic pattern and moderate seismic activity associated with the convergence between the African and Eurasian plates (Pelàez et al. 2006).

The northern Algeria, overlooking the Mediterranean Sea, is located near the interface between the Eurasian plate in the north and the African plate in the south. This interface, marked by a belt of seismic activity along the 36th parallel, is a seismically active zone that connects the islands of the Azores to Sicily across the north Maghreb (JICA, CGS 2006).

The region has experienced several destructive earthquakes in history, including the earthquakes of 1716 in Algiers (the epicenter of the intensity, Io X), 1825 to Blida (Io IX), 1790 to Oran (Io XI), 1889 to Mascara (Io IX), recently 1980 in El Asnam (Ms 7.3),
1989 in Tipasa (Ms 6.0), 1996 in Algiers (Ms 5.7), 1999 in Ain Temouchent (Ms 5.8), and more recently 2003 in Boumerdes (Ms 6.8). Figure 1 shows the distribution of earthquakes in Algeria.

Based on structural criteria and in consideration of the displacement of Western Europe independent of the rest of Eurasia, Albarello et al. (1995) suggest a relative displacement Afro-Iberian similar to the localization of Algiers of $5.5 \mathrm{~mm} / \mathrm{year}$ to $332^{\circ}$ azimuth.

\section{Methodology for seismic risk assessment and structural vulnerability evaluation in Algeria}

\subsection{Overview of the methodology}

The method of implementation of the scenario seismic event occurs in three principal steps Figure 2:

- The representation of seismic hazard;

- Analysis of the elements at risk and vulnerability assessment;

- The realization of one or several scenarios of seismic event.

The adopted methodology is based on a deterministic approach. The method depends on the characteristic earthquake model. The model suggests that the maxima earthquakes occurring at a particular

Table 2. Table of parameters, classes and weights considered by GNDT for RC buildings

\begin{tabular}{|c|c|c|c|c|c|}
\hline \multirow{2}{*}{ Vulnerability factors } & \multicolumn{3}{|c|}{ Class score } & \multicolumn{2}{|c|}{ Weight } \\
\hline & A & $\mathrm{B}$ & $\mathrm{C}$ & GNDT & Modifier weight \\
\hline 1. Resisting system type and organization of structure & 0 & 1 & 2 & 4 & 2 \\
\hline 2. Resisting system quality & 0 & 1 & 2 & 1 & 1 \\
\hline 3. Conventional resistance & -1 & 0 & 1 & 1 & 3 \\
\hline 4. Location and soil condition & 0 & 1 & 2 & 1 & 1 \\
\hline 5. Diaphragms & 0 & 1 & 2 & 1 & 1 \\
\hline 6. Plan configuration & 0 & 1 & 2 & 1 & 1 \\
\hline 7. Vertical configuration & 0 & 1 & 2 & 2 & 2 \\
\hline 8. Connectivity between elements & 0 & 1 & 2 & 1 & 2 \\
\hline 9. Low ductility structural members & 0 & 1 & 2 & 1 & 1 \\
\hline 10. Non structural elements & 0 & 1 & 2 & 1 & 1 \\
\hline 11. Preservation state & 0 & 1 & 2 & 2 & 2 \\
\hline
\end{tabular}




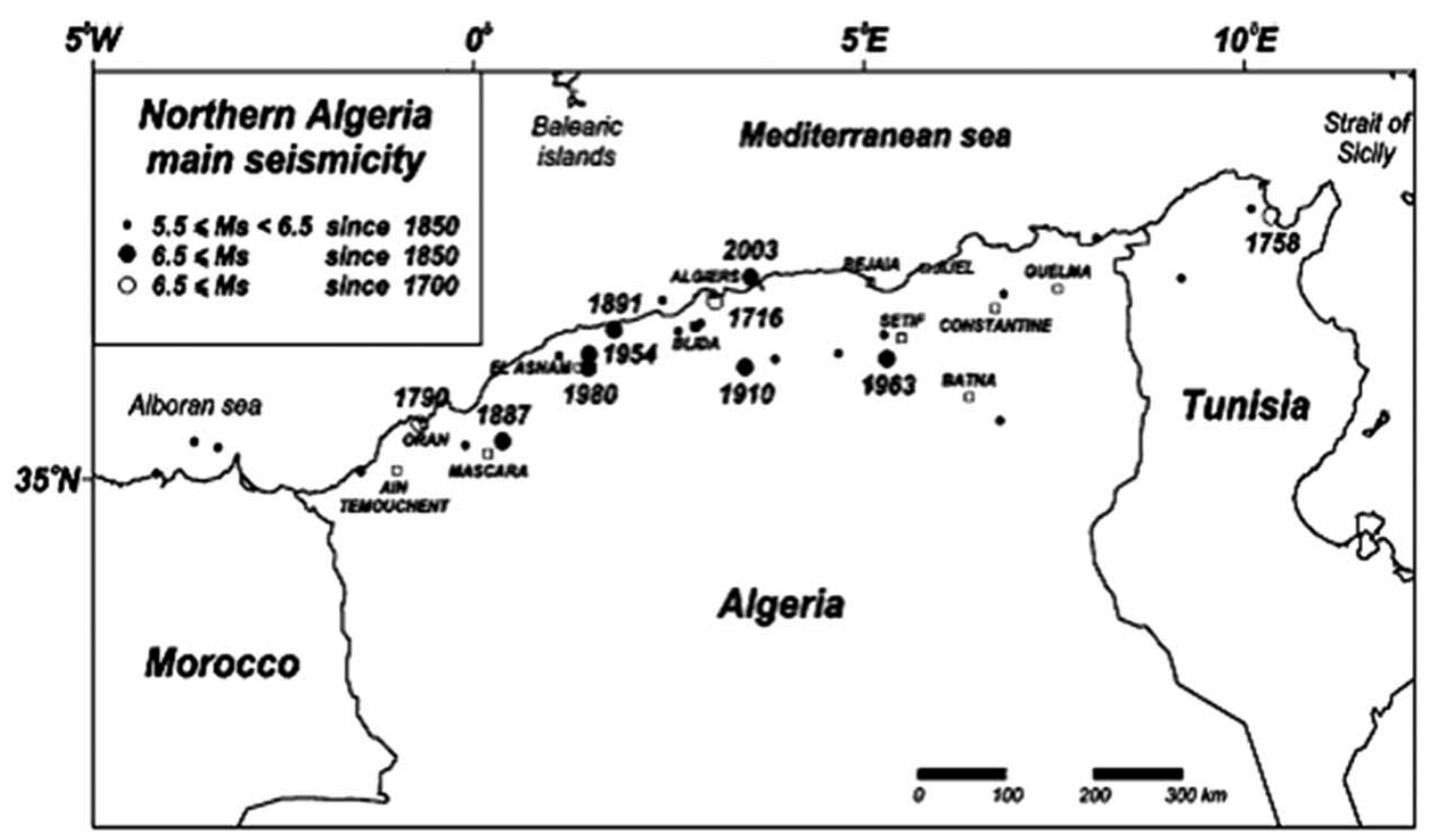

Fig. 1. Seismicity map in northern of Algeria (Peláez et al. 2006)

fault are in most cases with the same magnitude and the same intervals. This method involves the repeated occurrence of an earthquake that affected the study area in the past that took place repeatedly in the past and whose occurrence threatened again in the future.

\subsection{Seismic hazard identification}

The study of this phenomenon is based on knowledge of regional and local seismic hazard. The study of regional seismic hazard concerns the calculation of the probability for a region undergoing seismic intensity or level of acceleration given to a rocky horizontal (shaking not modified by local conditions).

In the study of the hazard analysis for local areas site effects are likely to occur, liquefaction and landslides. These areas are characterized by amplified earthquake in significant proportions. This amplification is

\section{hazard phenomena}

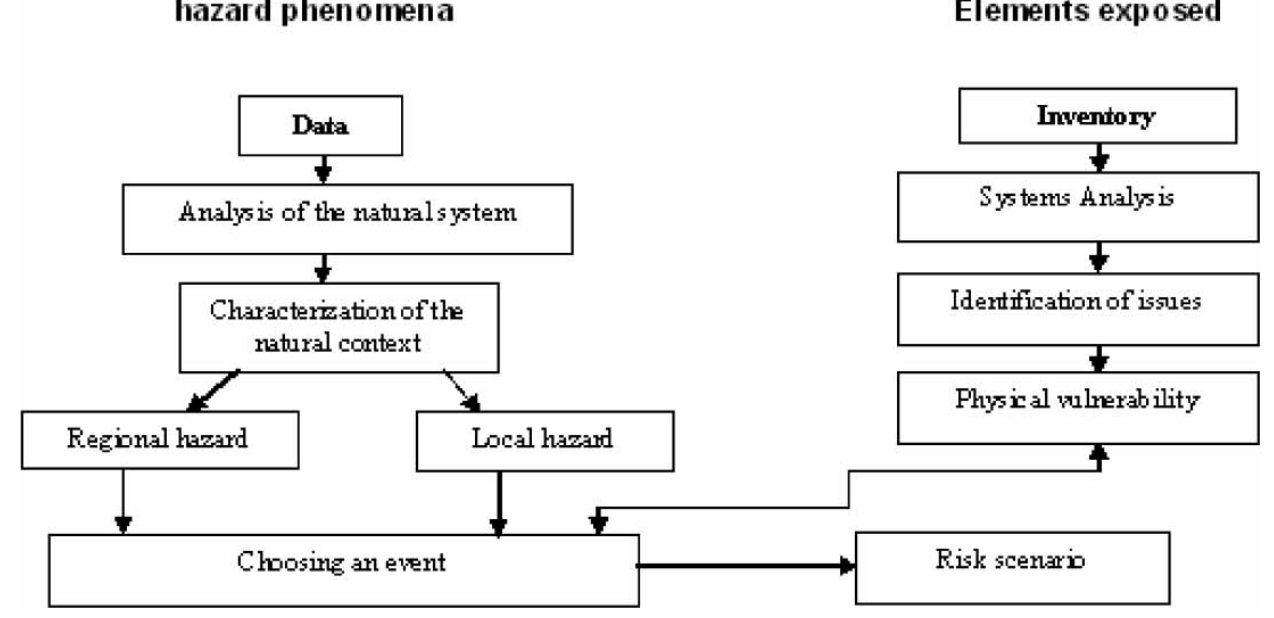

Fig. 2. Flowchart of the methodology for conducting a seismic scenario related either to the topography of the sites or to the soil rheology.

The physical parameters calculated for the scenario are acceleration and intensity felt in the area. From a seismic event magnitude and depth data, the acceleration on a rocky soil is calculated at all points of the study area, the micro-zoning is then taken into account by applying coefficients to the physical parameters to account the mechanical characteristic of some geological formations and the topography of the soil (Fig. 3).

The phenomena of liquefaction and landslides have been subject to assesment and their knowledge taken into account for any scenario.

\subsection{Vulnerability assessment of the buildings}

The analysis of the vulnerability of homes is based on the tasks described below.

\section{Elements exposed}




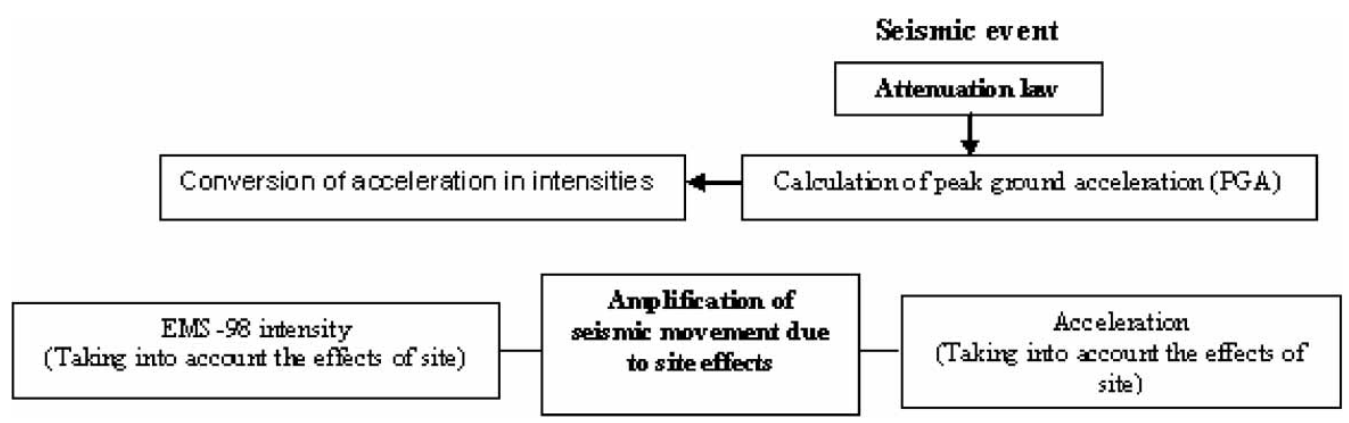

Fig. 3. Calculation of physical parameters

\subsubsection{Typology of the building}

The typology defined is based on the period, the type of construction and architectural criteria on buildings. Building Systems buildings are related to the construction period. Examples of buildings in Algeria are shown in Figure 4.

The main types of buildings held in northern Algeria are based on the following criteria:

- The number of floor: low rise (1-3 floors), of medium height (4-7 floors) and high-rise (eight stories) buildings;

- The type of construction, including construction of masonry and RC building;

- The construction period: <1981. 1981-1999, $>1999$.

In Algeria, the first seismic code was adopted after the 1980 earthquake in El Asnam-called RPA -81 (1981). In 1988, this code was revised to give RPA-88 (1988). The latest version is the 1999 RPA-99 (1999) which was amended after the earthquake of Boumerdes in 2003 and named RPA-99, version 2003 (2003). Therefore, a small proportion of the buildings were built with seismic design.

\subsubsection{Analysis of damage and collapse of buildings during recent earthquakes in Algeria}

The recent earthquakes in Algeria (El Asnam in 1980, Constantine in 1985, Tipaza in 1989, Mascara in 1994, Ain Benian in 1996, Ain Temouchent in 1999, and Boumerdes in 2003) show that most victims were injured by the collapse of buildings. These disasters have caused human and economic loss, particularly in urban area. The most important part of buildings was built without any consideration of seismic risk.

The damage rating for existing buildings in recent earthquakes will help to prevent the collapse of similar structures in other parts of Algeria.

Damage to the different types of construction in the two wilaya of Algiers and Boumerdes are very diverse. They can be broadly summarized as follows:

- Total or partial collapse of several buildings. In most cases, this level of crushing floor and first floor;

- Tilt of some buildings;
- Formation of plastic hinges at the column;

- Shearing of short columns;

- Total or partial collapse of masonry filling or façade;

- Buckling of RC columns;

- Crush and break by crushing under the strain of normal sections of the posts the stairwell;

- Separation of the concrete cover over part or the entire length of the posts;

- Local burst of concrete, cracking and breaking section in some shear walls, including elevator shafts;

- Damage caused by rattled between adjacent blocks due to insufficient seismic joint.

Several studies related to the definition and evaluation of earthquake damage after the recent earthquakes (EERI 2003; Bachtoula, Oussalem 2005; AFPS 2003) have argued that the damages and collapses are not due in significant deficiencies in the design code of Algeria, but had their origin in the quality of buildings.

\subsubsection{Structural vulnerability assessment}

The structural performance was evaluated by the vulnerability index. This procedure is based on the application of a hybrid index $I_{v}$, combining information description (typologic and qualitative) and quantitative information, based on the approach followed by the GNDT (Italian Group of defense against earthquakes). Without involving explicitly the vulnerability index, we could directly attribute the observed damage to a seismic intensity and a given site, the 11 parameters used in the method GNDT. We can then propose a multilinear regression (Bezzazi et al. 2008) without interaction which gives the index of damage $I_{\mathrm{D}}^{0}$ according to them as:

$$
I_{\mathrm{D}}^{0}=\alpha_{0}+\sum_{\mathrm{i}=1}^{11} \alpha_{\mathrm{i}} \cdot \mathrm{K}_{\mathrm{i}}
$$

where: $\alpha_{0}$ is associated with a vulnerability residual unexplained by 11 parameters; $\alpha \mathrm{i}, \mathrm{i}=1, \ldots, 11$ are the coefficients that depend on the seismic intensity and the site considered; $\mathrm{Ki}, \mathrm{i}=1, \ldots, 11$ are the qualifications assigned empirically to 11 parameters. 
One way to estimate the vulnerability index $\mathrm{IV}_{\mathrm{I}}$ is to put it equal to the index of the damage when setting the $I_{\mathrm{D}}^{0}$ observed seismic intensity and the site, including:

$$
I_{\mathrm{v}}=I_{\mathrm{D}}^{0}=\alpha_{0}+\sum_{\mathrm{i}=1}^{11} \alpha_{\mathrm{i}} \cdot \mathrm{K}_{\mathrm{i}}
$$

Rather than to follow this approach, which requires working with a large population of building, more sites and seismic intensities, we chosed to adapt, because of lack of data, empirically the original weights of the GNDT method (Tables 1 and 2) to better reflect the architectural differences between buildings in Italian and in the north of Algeria.

The proposed amendments were made to reflect the following findings from the damage of buildings during past earthquakes.

For masonry buildings:

(1) Type and organization of the resistance in the case of masonry buildings located in Algeria does not have a high variability. We, therefore, propose to pass for the weight of this parameter from 1.5 to 1 ;

(2) The presence of load-bearing walls of a traditional masonry not chained. We propose the passage of this parameter from 0.25 to 0.5 ;

(3) The conventional resistance is doubly touched by a material with very low resistance and poor preservation, we propose to spend for this parameter from 1.5 to 1.75 .

For RC buildings:

(1) The organization of the resistance in the case of RC buildings located in Algeria is not of great variability, we propose to pass for this parameter from 4 to 2 ;

(2) The conventional resistance is twice hit by a very low resistance of the concrete structure (14-17) MPa observed in the samples (algerian design code requires $25 \mathrm{MPa}$ ) and the lack of seismic conception, we propose to increase for this parameter from 1 to 3 ;

(3) The existence of flexible floor: a flexible floor in a building usually presenting a defect at the ground floor which is generally used as a commercial space. We propose to increase for this parameter from 1 to 2 .

\subsection{Damage estimation}

For physical damage to the building, the EMS-98 (European Macroseismic Scale 1998) damage grades have been considered, describing the observed damage for structural and non structural components. Five damage grades are identified $-\mathrm{Dk}(\mathrm{k}=0 / 5)$ : $\mathrm{D} 1$ slight, D2 moderate, D3 heavy, D4 very heavy, D5 destruction, plus the absence of damage D0 no damage.
A kind of mean damage grade, $\mu_{\mathrm{D}}$ (Lagomarsino, Giovinazzi 2006), permits to illustrate absolutely the expected damage for a building, known its vulnerability and for a given intensity:

$$
\mu_{\mathrm{D}}=2.5\left[1+\tanh \left(\frac{I+6.25 \mathrm{~V}_{\mathrm{I}}-13.1}{2.3}\right)\right],
$$

where: $I$ is the contribution provided in terms of seismic intensity macroseimic: $\mathrm{V}_{\mathrm{I}}$, and the index of vulnerability.

\section{Application of proposed methodology}

\subsection{The study area}

Oran, Algeria's second city after the capital Algiers, is located northwest of the country on the shores of the Mediterranean, important economical and industrial pole, rich in history and architecture, home to achievements of urban and architectural value.

A number of buildings (such as pilot units) were selected to evaluate in detail the seismic actions on buildings. The study area includes the buildings of the district Oussama (Ex - Medioni) of the city. The area is bounded on the east by Avenue of the ANP, to the west by Abed Hamamouche Street, north by Mustapha Benboulaid Avenue and south by the Soufi Zoubida street (Fig. 5). This test zone has the advantage of bringing together different types of buildings in a relatively small area of suitable size for the study on the seismic risk.

\subsection{Implementation of the scenario}

The regional hazard assessment has been studied in other works (Bouhadad, Laouami 2002). The regional hazard area is presented in terms of average horizontal acceleration in the form of zoning maps for return periods of 200 years and 500 years (Fig. 6). The value of seismic hazard is over $0.40 \mathrm{~g}$ on the set Oran coast for a return period of 500 years.

The study takes into account local hazard data immediately available (this is a first-level microzoning) (Fig. 7): Geological map 1:500000; Elevation Model map.

For Macroseismic intensity scenario, the calculation of the movement of the substratum is based on the application of the empirical attenuation function of Ambraseys et al. (2005). This function allows the calculation of the horizontal Peak Ground Acceleration (PGA) and response spectra for earthquakes for which the moment magnitude $(\mathrm{Mw})$ is between 5.0 and 7.6, for distances up to the surface projection of the fault range 0 to $100 \mathrm{~km}$. This relationship reflects the type of soil (rock/ hard soil/ soft soil). The development of this function is based on data from Europe and the Middle East and North Africa including 15 Algerian recordings. 


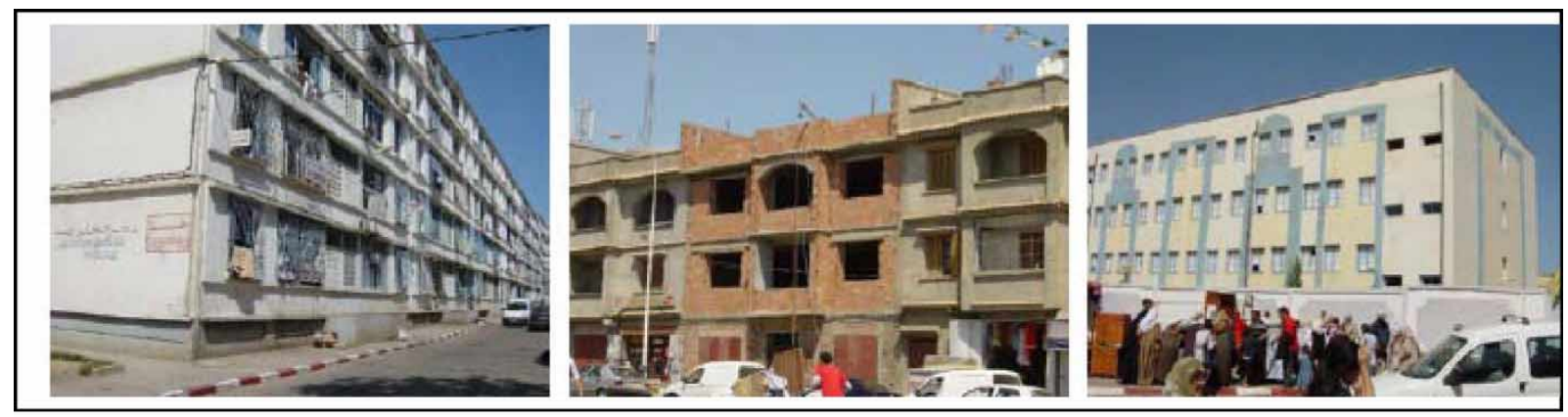

(1) Houses with crawl space

(2) Houses and shops

(3) School Reinforced concrete buildings
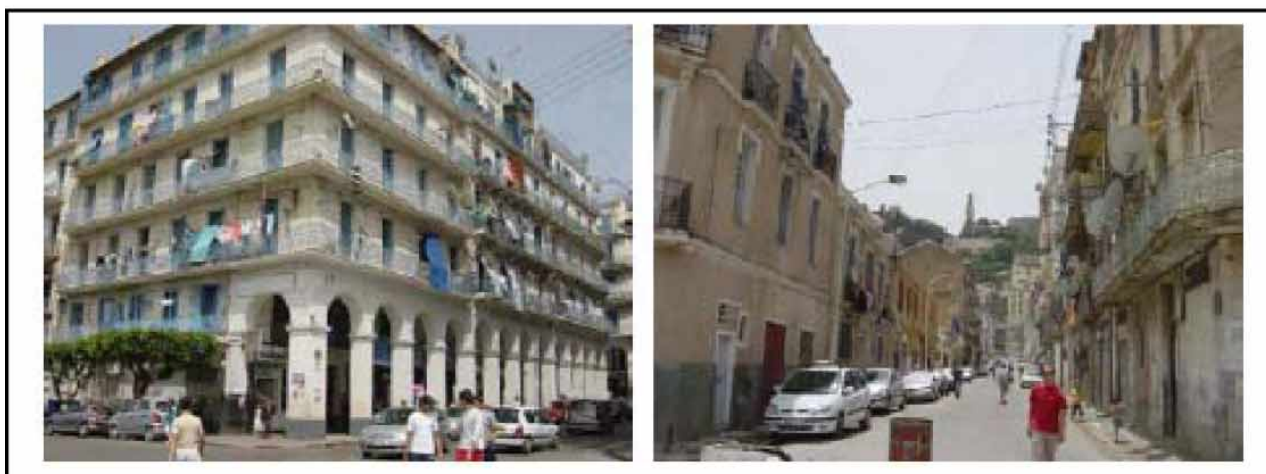

(1) Houses and shops

(2) Houses

Masonry buildings

Fig. 4. Examples of constructions in Algeria (JICA, CGS 2006)

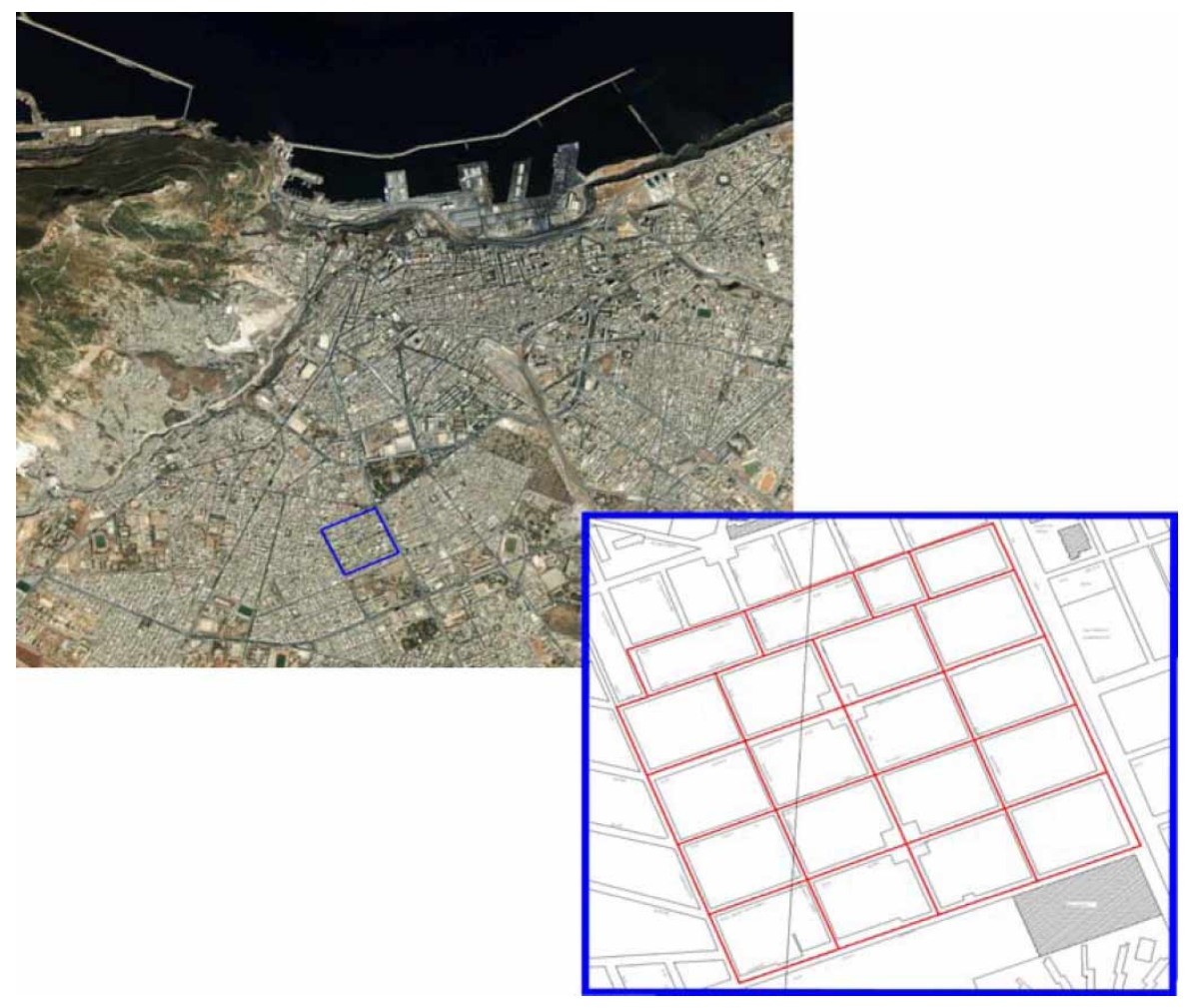

Fig. 5. Study area identification 

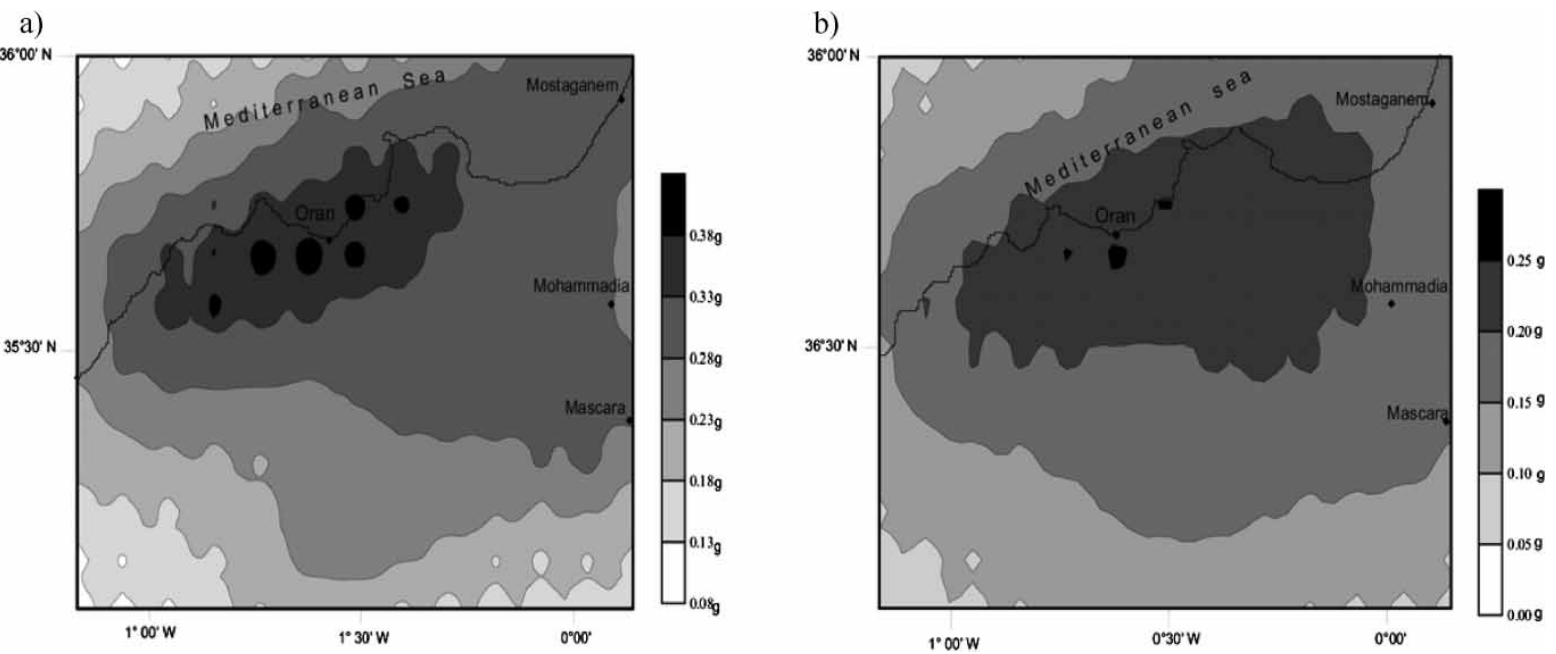

Fig. 6. Seismic zoning map in terms of values of Peak Ground Accelerations of the Oran region (Bouhadad, Laouami 2002): (a) for a return period of 200 years; (b) for a return period of 500 years

We present a deterministic approach based on the definition of an earthquake reference also called seismic scenario. This corresponds to the historical earthquake that generated the most theoretically strong vibrations in the region of Oran. A search of the CRAAG database (1994) (Table 3) was used to select the earthquake of 1790 in Oran. The epicentral intensity is estimated at $\mathrm{X}$. The earthquake caused many victims $(3,000$ dead) in the city and destruction in the coastal towns and surrounding villages.

a)

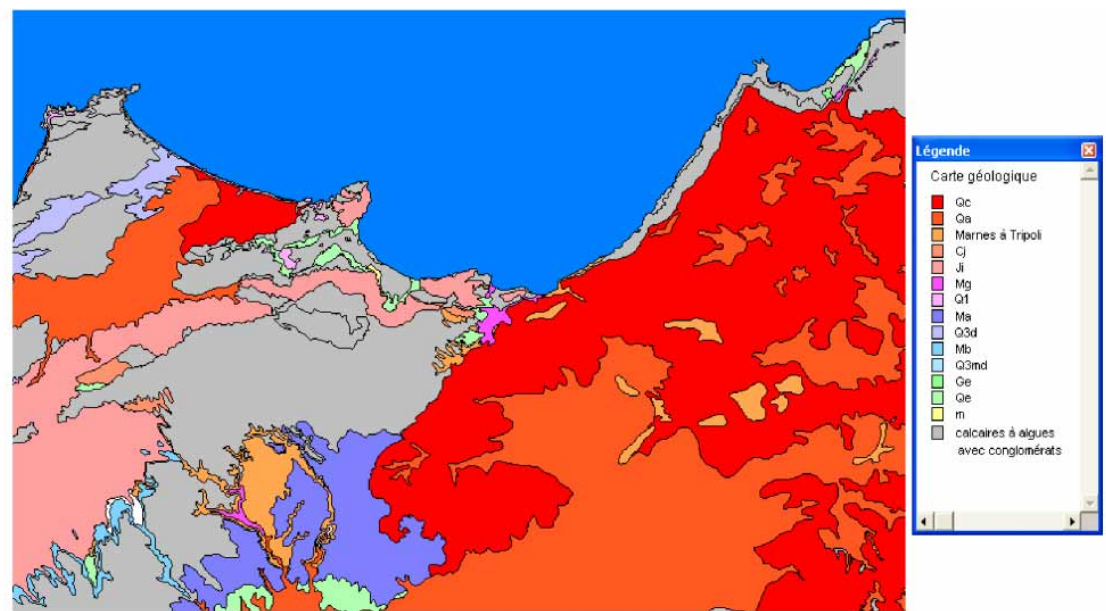

b)

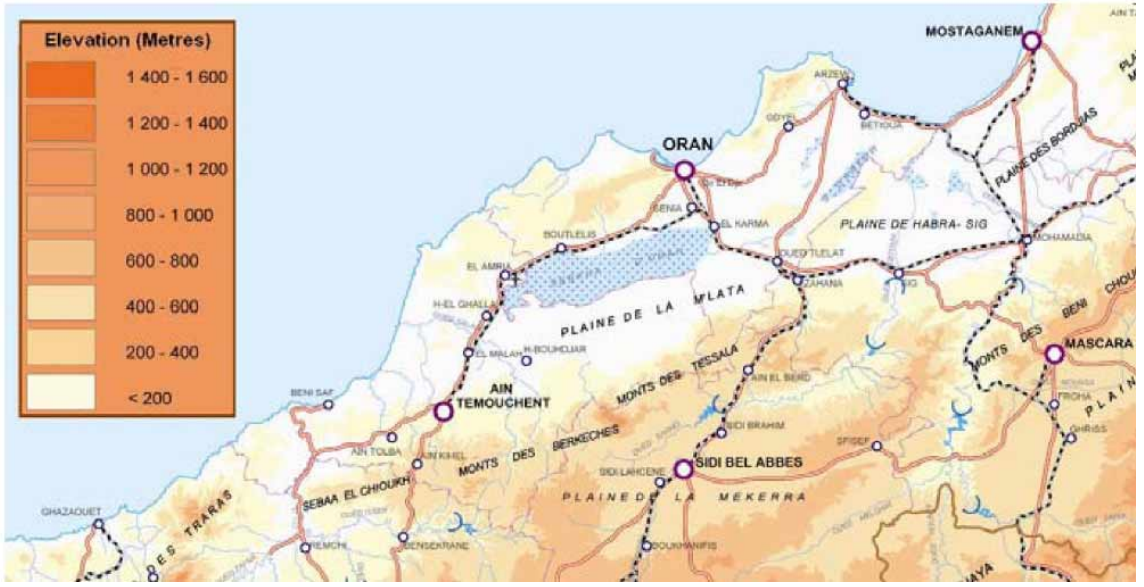

Fig. 7. Geology-based zonation for the sub-regional area (a); Elevation Model (b) 
Table 3. Historical seismicity of the Oranie region with $\mathrm{I} 0 \geq$ VII (CRAAG 1994)

\begin{tabular}{llrr}
\hline Date & Long & \multicolumn{1}{c}{ Lat } & $\mathrm{I}_{0}$ \\
\hline 09101790 & 35.70 & -00.70 & X \\
00031819 & 35.40 & 00.10 & VIII \\
22111851 & 35.40 & 00.10 & VIII \\
26071861 & 35.70 & -00.60 & VII \\
29071872 & 35.90 & 00.10 & VII \\
29111887 & 35.583 & 00.33 & IX \\
21051889 & 35.70 & 00.80 & VII \\
30071890 & 35.70 & 00.50 & VII \\
24081928 & 35.90 & 00.60 & VIII \\
\hline
\end{tabular}

To perform the analysis of seismic vulnerability, information on the housing stock is necessary. The data for each building containing the following information:

- General information (address, age, etc.);

- Geometrical characteristics;

- Structural system;

- Soil conditions.

Data on these buildings have been digitized in a database through the investigations forms.

The survey of building inventory for existing buildings is to obtain data on the distribution of types of buildings (Fig. 8).

The results emerging from this survey are:

- The majority of buildings are in RC;

- Most of the masonry buildings were built before 1981;
- Most of RC buildings were built according to a pre-code without any seismic consideration;

- The majority of masonry buildings are composed made of one or two floors.

The methodology can be applied in digital form (Fig. 9), survey information is automatically stored in a table database. It is accessed by programs to calculate load factors for each building. Then we chose the combination of factor index. Finally, we calculate the vulnerability class and degree of damage.

A GIS was used to perform a comprehensive analysis of risk by integrating relational database containing an inventory of buildings.

\section{Results and discussions}

\subsection{Risk estimation}

Figure 10 shows the map of maximum intensity (EMS 98 2001). As the soil of the city of Oran is mainly composed of unconsolidated deposits (recent alluvial formations), we see greater or lesser intensities ranging from IX to VIII.

This type of analysis allows us to give each building a class of vulnerability similar to those defined by the macroseismic scales as MSK and EMS-98 (Fig. 11). Table 4 shows the six classes considered in this study. A qualitative description of the characteristics of the building is given for each class.
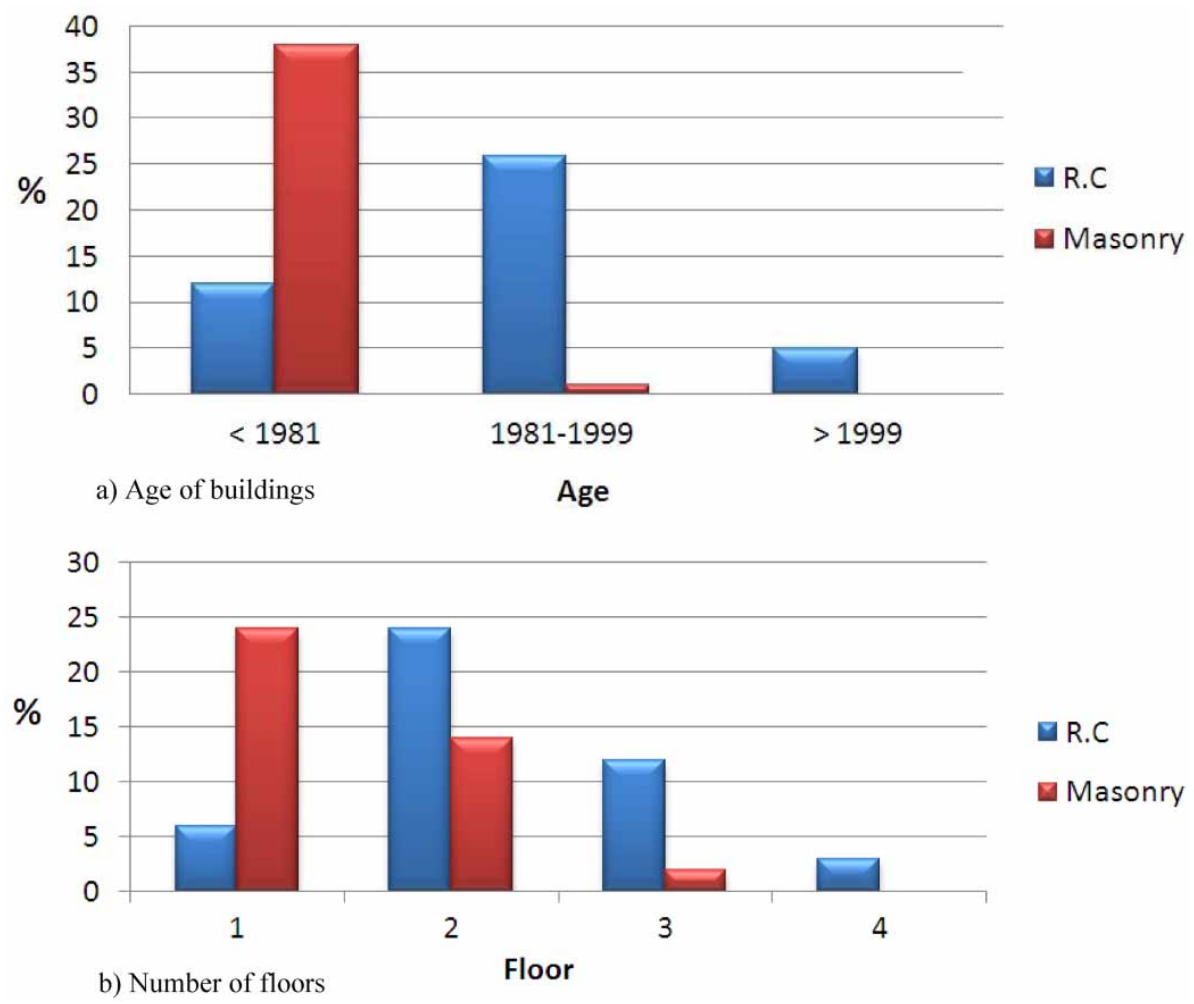

Fig. 8. Types of buildings 


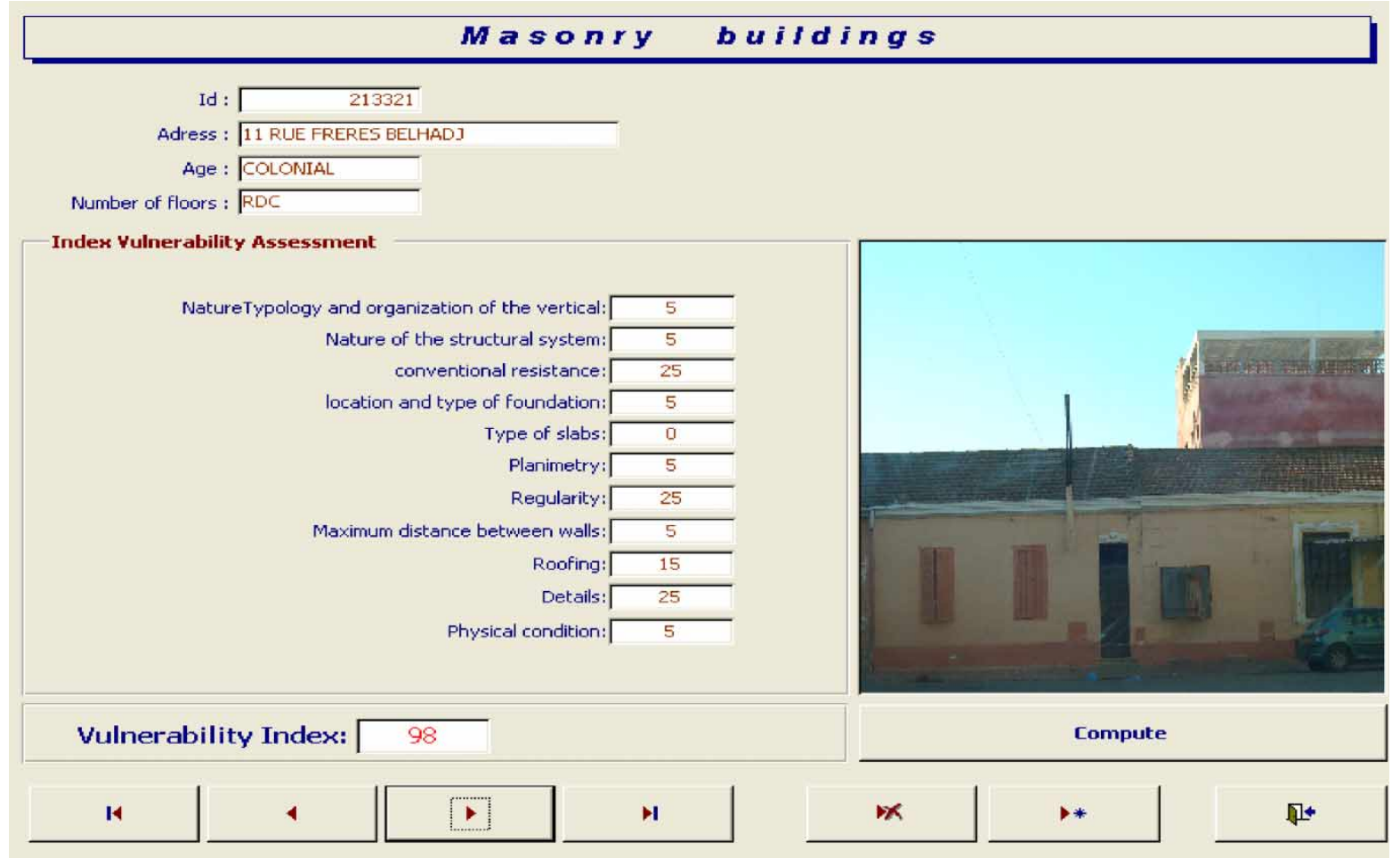

Fig. 9. Typical structural performance form for the buildings

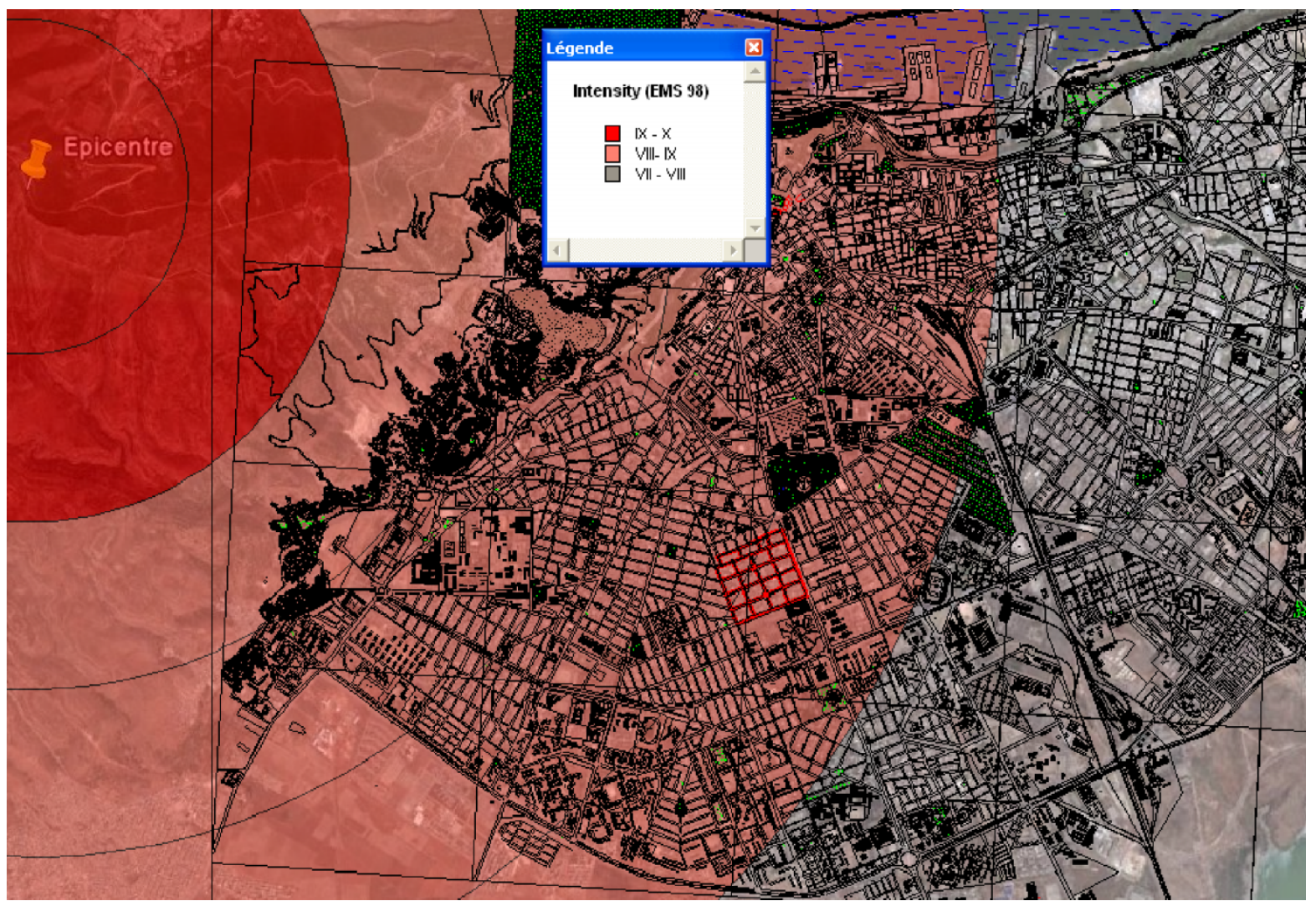

Fig. 10. $\mathrm{I}_{\mathrm{EMS}-98}$ deterministic hazard scenario for the 1790 event 


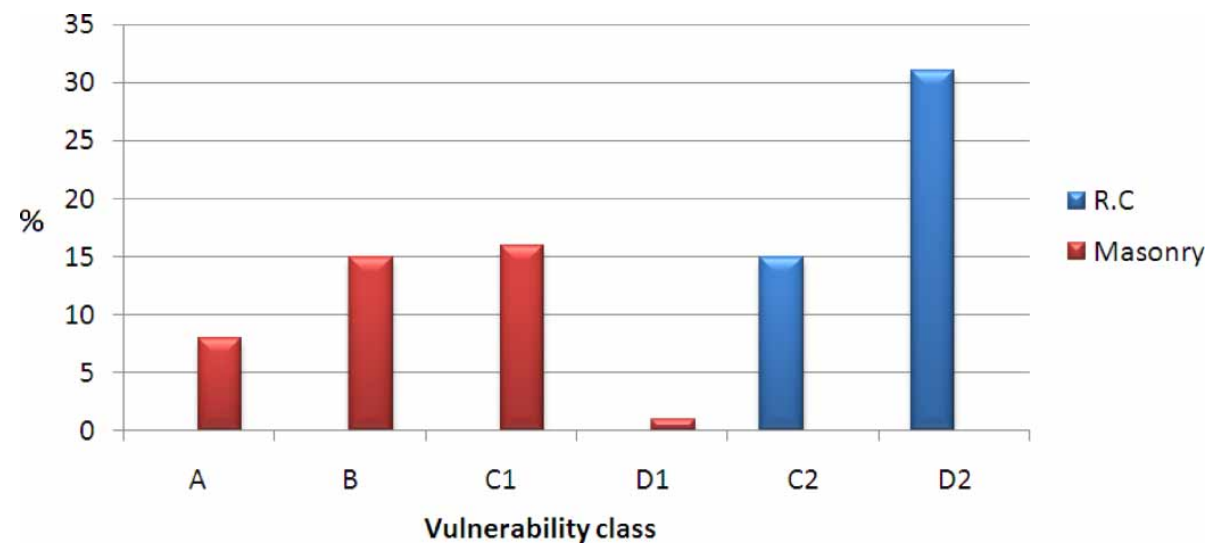

Fig. 11. Frequency distribution of buildings surveyed for typological construction types

The results from this study are as follows: For masonry buildings. A single masonry building has been repaired following a seismic code. This is explained by the scarcity of seismic retrofit of existing buildings and the massive use of RC.

Forty percent of masonry buildings represent a quality which varies of good to means with the presence of rigid floor.

Remaining $60 \%$ is shared between class A and B. This is explained by the low conservation status or the presence of flexible floor.

For RC buildings. Sixty-seven percent (more than half) of $\mathrm{RC}$ buildings were designed according to seismic code. This is explained by two factors:

- The introduction of paraseismic code after the earthquake of chlef in 1980;

- The construction of these buildings after 1981.

Figure 12 shows the index of relative vulnerability obtained from the ratio of the vulnerability index calculated on the vulnerability index maximum:

$$
I_{\mathrm{v}} \text { relative }=\frac{I_{\mathrm{v}} \text { calcule }}{I_{\mathrm{v}} \max } .
$$

The vulnerability of masonry buildings (Class A) ranges from moderate to high. This can be explained by the poor quality of masonry saw the dilapidation, the lack of conservation of buildings and the existence of flexible floor. The vulnerability of masonry buildings (Class B) has an average given their vulnerability status globally means. One masonry building (Class
D1) has a low vulnerability due to its recent rehabilitation.

Half of the RC buildings (Class D2) has an average seismic vulnerability $\left(I_{\mathrm{v}}\right.$ varies ente 0.4 and 0.6). This can be explained by the design of the buildings following a pre-code.

The vulnerability of RC buildings (Class C2) varies from medium to high; this can be explained by the lack of any seismic arrangement.

\subsection{Damage estimation}

The results of the scenario simulation of damage are provided in Figs 13 and 14 in terms of degrees of damage, confirm the effectiveness of an intervention renovation significantly reducing the effects of earthquakes.

It appears from this analysis of seismic risk that:

(1) The grade of damage of RC buildings range from D2 to D4. Over $95 \%$ of buildings have moderate damage that result in earthquakes through cracks in the columns and beams with detachment or not pieces of concrete, cracks in partition walls and fall of fragile pieces (siding and plaster). The remaining presents significant damage, which in case of earthquake, result in the destruction of concrete and rebar breaks, partial collapse; tilt columns. This is explained by the fact that the construction of these buildings in a seismic

Table 4. Vulnerability classes defined according to criteria similar to those used for the MSK and EMS-98 scales for the typological classification of buildings

\begin{tabular}{ll}
\hline Vulnerability class & \multicolumn{1}{c}{ Description } \\
\hline A & Poor or average quality masonry with flexible floors \\
B & Poor or average quality masonry with rigid floors or good quality masonry with flexible floor \\
C1 & Average or good quality masonry with rigid floor \\
D1 & Masonry buildings repaired or designed according to the seismic code \\
C2 & RC buildings \\
D2 & RC buildings designed according to the seismic code \\
\hline
\end{tabular}




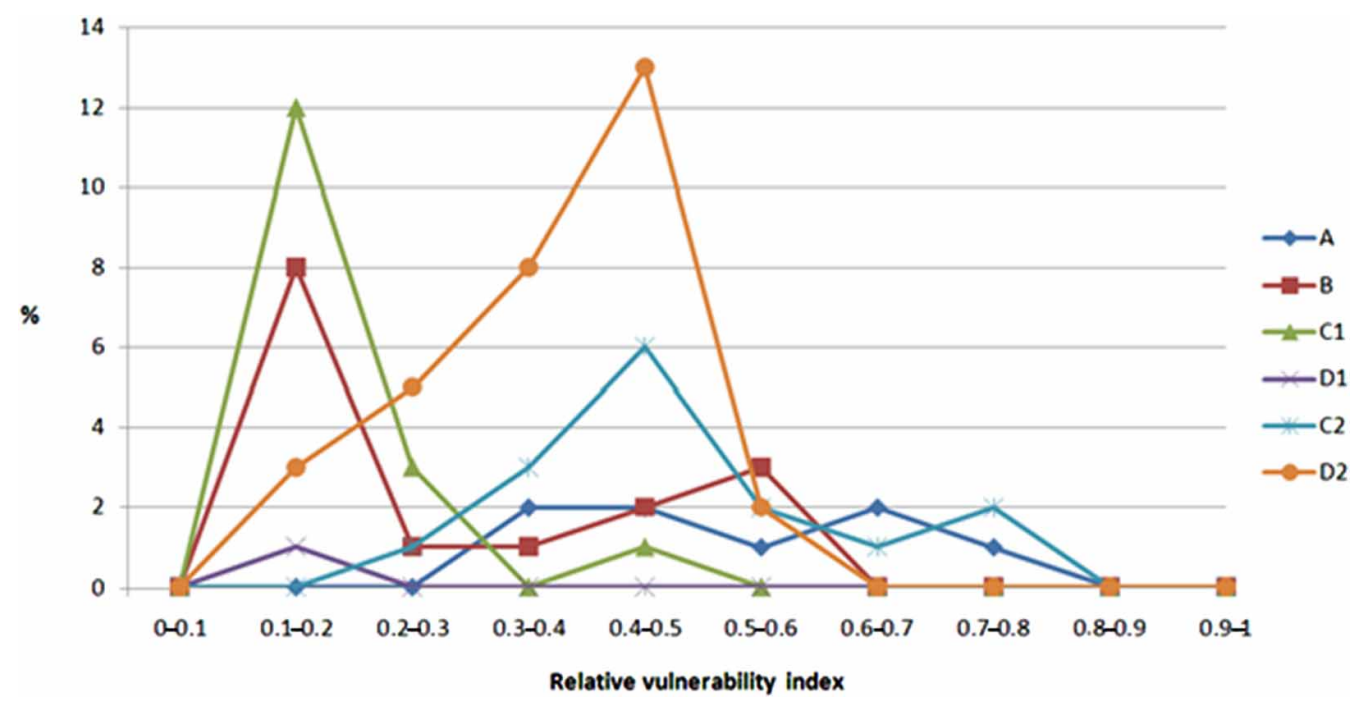

Fig. 12. The distribution of the relative index vulnerability in the typological classes of vulnerability

code, the date of construction of these buildings is later than 1981.

(2) The grade of damage to masonry buildings varies from D3 to D5. Over $37 \%$ of the buildings present a partial or total destruction in an earthquake. Over $32 \%$ of the buildings has resulted in significant damage walls and weak that a partial failure of the structure. The remaining presentes moderate damage that result in large cracks in most walls, sliding tiles and a failure of individual non structural elements.

Several factors affect the rate of damage advanced buildings:

- their conventional low resistance;

- the presence of non chained walls to traditional masonry;

- the low conservation and dilapidated buildings;

- any seismic disposition was taken into account in this type of construction.

\section{Conclusions}

The analysis of seismic risk in Oran city was an opportunity to develop a tool for construction of scenario proper to the characteristics of Oran region. This can be a important element in the context of strengthening the old patrimony and the establishment of prevention and management plans of disaster in the short, medium, and long term.

In order to apply the method on large areas, the data needed to establish the scenario is simple and evaluative. The method allows to construct quickly the scenario, but the result implies a fairly large uncertainty is difficult to quantify. However, more input data scenario is accurate and uncertainties can be reduced. Thus, by improving the definition of triggers induced phenomena (taking into account the effects of site, accelerating the propagation of the acceleration at the rock and vulnerability assessment), it is certainly possible to achieve more accurate. This method cost of

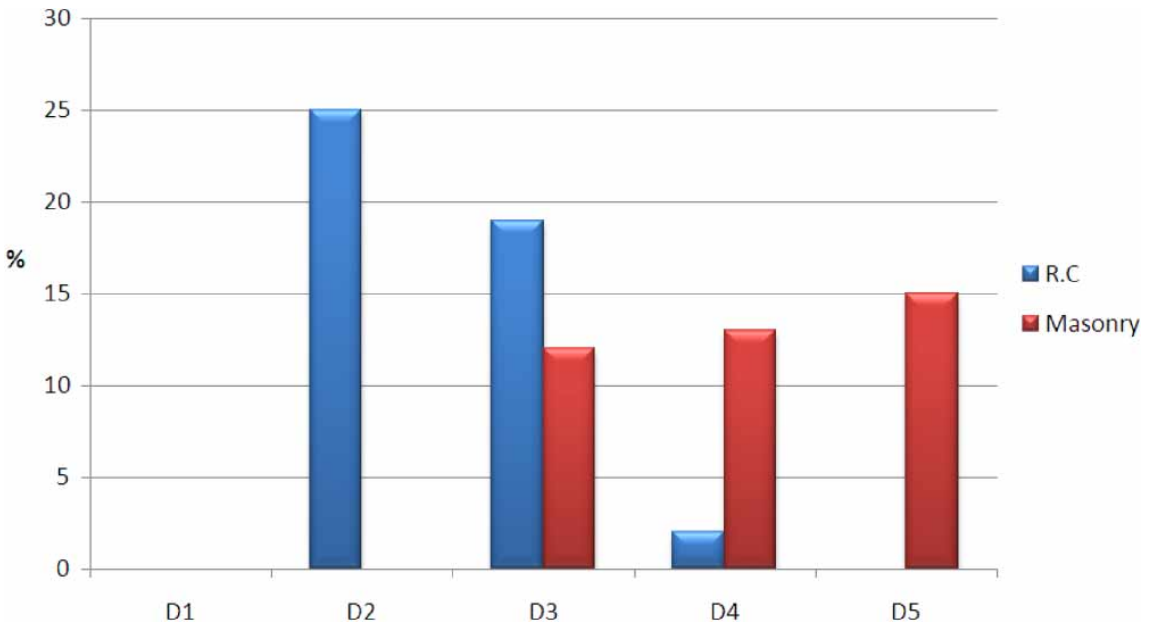

Fig. 13. Building damage from selected scenarios 


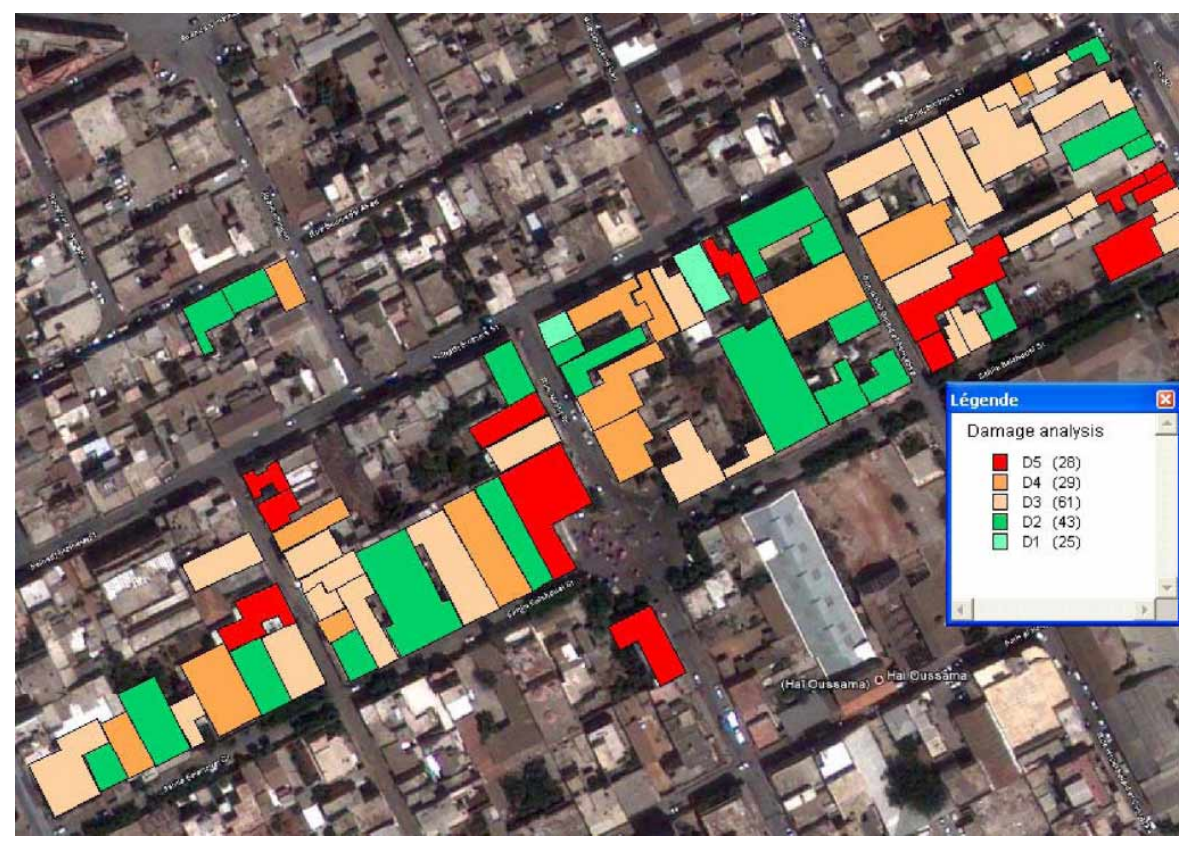

Fig. 14. Map of damage grade

having a first ranking of vulnerability to a group of buildings, avoiding the more sophisticated and expensive studies, focused on groups of buildings appear to be most vulnerable. One limitation of the method lies in the fact of considering only the seismic intensity or PGA in place of the full spectrum of ground motion, while the resonance phenomena observed during the earthquake are to specific frequencies depending on the site and buildings. Nevertheless, the scenario presented here gives a first idea of what could result in the city of Oran earthquake identical to that of 1790. On the other hand, with a high vulnerability, the damage estimates are quite significant especially for masonry buildings.

Further analysis would estimate the economic and humans costs. This analysis must take into account the number of tourists, which varies greatly in the city of Oran at different times of the year (school periods, public holidays, summer vacation, etc.) and time (day, night, lunch periods, etc.). Similarly, the vulnerability analysis of networks and means of communication as well as a detailed analysis of the vulnerability of structures with high stakes considered fragile in the first approach should help provide comfort measures priority and so reduce term the exposure of people and property to seismic risk.

\section{References}

Albarello, D.; Mantovani, E.; Babbucci, D.; Tamburelli, C. 1995. Africa-Eurasia kinematics: main constraints and uncertainties, Tectonophysics 243(1-2): 25-36. http://dx.doi.org/10.1016/0040-1951(94)00189-G

AFPS. 2003. Le séisme du 21 Mai 2003 en Algerie, Rapport préliminaire de la mission AFPS. [The earthquake of May 21, 2003 in Algeria. Preliminary Report of the mission AFPS]. Association Française de Génie Parasismique, 2003.

Ambraseys, N. N.; Douglas, J.; Sarma, S. K.; Smit, P. M. 2005. Equations for the estimation of strong ground motion from shallow earthquakes using data from Europe and the Middle East: horizontal peak ground acceleration and spectral acceleration, Bulletin of Earthquake Engineering 3(1): 1-53. http://dx.doi.org/10.1007/s10518-005-0183-0

André, G.; Chiroiu, L.; Guillande, R. 2001. Evaluation de dommages dus au séisme de Gujarat, Inde 2001 à partir de l'imagerie SPOT 5 [Evaluation of damage caused by earthquake in Gujarat, India in 2001 from SPOT 5 imagery, in Colloque SPOT 5 "Vers des nouvelles applications" [SPOT 5 Colloqum "Towards new applications"]. Toulouse, France.

ATC-13: Earthquake damage evaluation data for California. Applied Technology Council Report. Redwood City, California. 1985. $486 \mathrm{p}$.

ATC-21: Rapid visual screening of buildings for potential seismic hazards: a handbook. FEMA-145, Applied Technology Council Report. Redwood City, California. 1988. $131 \mathrm{p}$.

Augusti, G.; Ciampoli, M. 2000. Heritage buildings and seismic reliability, Progress in Structural Engineering and Materials 2(2): 225-237.

http://dx.doi.org/10.1002/1528-2716(200004/06)2:2 <2 25::AID-PSE28 > 3.0.CO;2-5

Bachtoula, H.; Oussalem, H. 2005. The 21 may 2003 ZEMOURI (Algeria) earthquake: damage and disaster reponses, Journal of Advanced Concrete Technology 3(1): 161-174. http://dx.doi.org/10.3151/jact.3.161

Bezzazi, M.; Khamlichi, A.; Gonzalez, J. R. A. 2008. Vulnérabilité sismique des constructions de type béton armé au nord du Maroc [Seismic vulnerability of reinforced concrete construction type in northern Morocco], Canadian Journal of Civil Engineering 35(6): 600-608. http://dx.doi.org/10.1139/L08-010 
Bendimerad, F. 2001. Loss estimation: a powerful tool for risk assessment and mitigation, Soil Dynamics and Earthquake Engineering 21(5): 467-472. http://dx.doi.org/10.1016/S0267-7261(01)00022-7

Benedetti, D.; Petrini, V. 1984. On seismic vulnerability of masonry buildings: proposal of an evaluation procedure, L'Industria delle Costruzioni 18: 66-78.

Bouhadad, Y.; Laouami, N. 2002. Earthquake hazard assessment in the Oran Region (Northwest Algeria), Natural Hazards 26(3): 227-243. http://dx.doi.org/10.1023/A:1015602815231

Braga, F.; Liberatore, D. M. 1982. A statistical study on damaged buildings and ensuing review of the MSK-76 scale, in Proc. of the 7th European Conference on Earthquake Engineering, Athens, Greece, 431-450.

Calvi, G. M.; Pinho, R.; Magenes, G.; Bommer, J. J.; Restrepo-Vélez, L. F.; Crowley, H. 2006. Development of seismic vulnerability assessment methodologies over the past 30 years, ISET Journal of Earthquake Technology 43(3): 75-104.

Coburn, A. W.; Spence, R. 2002. Earthquake protection. Chichester: John Wiley \& Sons Ltd. 436 p. http://dx.doi.org/10.1002/0470855185

Chopra, A. K.; Goel, R. K. 1999. Capacity-DemandDiagram methods based on inelastic spectrum, Earthquake Spectra 15(4): 637-656. http://dx.doi.org/10.1193/1.1586065

CNR. 1993. Rilevamento della Vulnerabilita degli Edifici in Muratura, Appendice No 2 alla Pubblicazione "Rischio Sismico di Edifici Pubblici Parte I - Aspetti Metodologici" [Detecting the Vulnerability of Masonry Buildings, Appendix No. 2 to Publication "Seismic Risk of Public Buildings Part I - Methodological Aspects"]. Consiglio Nazionale delle Ricerche (CNR), Gruppo Nazionale per la Difesa Dai Terremoti (GNDT), Roma, Italia, 1993.

CRAAG, 1994. Les seismes en Algerie de 1365 a' 1992 [The Earthquakes in Algeria from 1365 to 1992]. CRAAG Centre de Recherche en Astronomie, Astrophysique et de Geophysique Report, Algiers.

EMS 98 L'Echelle Macrosismique Européenne 1998 [The European Macroseismic Scale 1998]. Conseil de l'Europe, Cahiers du Centre Européen de Géodynamique et de Séismologie, Vol. 19, 2001.

EERI. 2003. The Boumerdes, Algeria earthquake of May 21, 2003. Reconnaissance Report, Learning from Earthquakes Program. Earthquake Engineering Research Institute. $57 \mathrm{p}$.

FEMA. 2002. Rapid visual screening of buildings for potential seismic hazards: supporting documentation. Report No. FEMA 155. 2nd ed. Washington, DC: Buildings Seismic Safety Council. Developed for the Federal Emergency Management Agency. 137 p.

Giovinazzi, S. 2005. The vulnerability assessment and the damage scenario in seimic risk analysis. $\mathrm{PhD}$ thesis. Department of Civil Engineering of the Technical University Carolo-Wilhelmina at Braunschweig and Department of Civil Engineering of the University of Florence.

GNDT. 1986. Instruzioni per la Compilazione della Scheda di relivamento Esposizione e Vulnerabilitá Sismica Degli Edifici [Instructions for completing the survey form to display the seismic vulnerability of buildings]. Gruppo Nazionale per la Difesa dai Terremoti, Regione Emilia Romana, Italie, 1986.

GNDT. 1994. Scheda di esposizione e vulnerabilità e di rilevamento danni di primo livello e secondo livello (muratura e cemento armato) [Sheet exposure and vulnerability and damage detection of the first level and second level (masonry and concrete)]. Gruppo Nazionale per la Difesa dai Terremoti, Roma, 1994.

HAZUS-1999: Earthquake loss estimation methodology technical and user manuals. Federal Emergency Management Agency, Washington, DC

Lagomarsino, S.; Giovinazzi, S. 2006. Macroseismic and mechanical models for the vulnerability assessment of current buildings, Bulletin of Earthquake Engineering 4(4): 415-443.

http://dx.doi.org/10.1007/s10518-006-9024-z

JICA; CGS. 2006. A study of seismic microzoning of the Wilaya of Algiers in the People's Democratic Republic of Algeria. Final Report, Vol. 2, Oyo International Corporation, Nippon Koei Co., Ltd.

Karaman, H.; Şahin, M.; Elnashai, A. S.; Pineda, O. 2008. Loss assessment study for the Zeytinburnu District of Istanbul using Maeviz-Istanbul (HAZTURK), Journal of Earthquake Engineering 12(1): 187-198. http://dx.doi.org/10.1080/13632460802014030

Korkmaz, K. A. 2009. Earthquake disaster risk assessment and evaluation for Turkey, Environmental Geology 57(2): 307-320. http://dx.doi.org/10.1007/s00254-008-1439-1

Korkmaz, K. A.; Kutay, E. M. 2010. Automated hazard assessment techniques using satellite images following the 2008 Sichuan China Earthquake, Human and Ecological Risk Assessment: an International Journal 16(3): 463-477.

McCormack, T.; Rad, F. N. 1997. An earthquake loss estimation methodology for buildings based on ATC-13 and ATC-21, Earthquake Spectra 13(4): 605-621. http://dx.doi.org/10.1193/1.1585971

Molina, S.; Lindholm, C. 2005. A logic tree extension of the capacity spectrum method developed to estimate seismic risk in Oslo, Norway, Journal of Earthquake Engineering 9(6): 877-897. http://dx.doi.org/10.1080/13632460509350570

Molina, S.; Lang, D. H.; Lindholm, C. 2008. User and technical manual, SELENA v4.0. NORSAR, Kjeller, Norway.

Mouroux, P.; Bertrand, E.; Bour, M.; Le Brun, B.; Depinois, S.; Masure, P. 2004. RISK-UE team. The European RiskUE Project: an advanced approach to earthquake risk scenarios, in Proc. of the $13^{\text {th }}$ World Conference on Earthquake Engineering, Vancouver, Canada, Paper No. 3329.

Mouroux, P.; Le Brun, B. 2006. Presentation of RISK-UE project, Bulletin of Earthquake Engineering 4(4): $323-$ 339. http://dx.doi.org/10.1007/s10518-006-9020-3

NRC-IRC-1992 Manual for screening of buildings for seismic investigation. Institute for Research in construction, National research council Canada, Ottawa, ON, 1992.

Peláez, A.; Hamadache, M.; Casado, C. L. 2006. Seismic hazard in terms of spectral accelerations and uniform hazard spectra in Northern Algeria, Pure and Applied 
Geophysics 163(1): 119-135.

http://dx.doi.org/10.1007/s00024-005-0011-0

RADIUS 1999: Risk assessment tools for diagnosis of urban areas against seismic disasters. United Nations Initiative towards Earthquake Safe Cities, 1999.

RISK-UE 2004: The European Risk-Ue Project: an advanced approach to earthquake risk scenarios (2001-2004). http://www.risk-ue.net

Rosetto, T.; Elnashai, A. S. 2003. Derivation of vulnerability functions for european-type RC structures based on observational data, Engineering Structures 25: 1241-1263.

http://dx.doi.org/10.1016/S0141-0296(03)00060-9
RPA-81: Règles parasismiques algériennes [Rules of Algerian earthquake]. CGS, Algeria, 1981.

RPA-88: Règles parasismiques algériennes [Rules of Algerian earthquake]. CGS, Algeria, 1988.

RPA-99: Règles parasismiques algériennes [Rules of Algerian earthquake]. CGS, Algeria, 1999.

RPA VERSION 2003: Règles parasismiques algériennes [Rules of Algerian earthquake]. CGS, Algeria, 2003.

Yeh, C.-H.; Loh, C.-H.; Tsai, K.-C. 2006. Overview of Taiwan earthquake loss estimation system, Nat Hazards 37(1-2): 23-37.

http://dx.doi.org/10.1007/s11069-005-4654-z

Fatima Zohra BABA HAMED. Assistant Professor at the Department of Civil Engineering at Oran University of Sciences and Technology. Her primary research interests include assessment of structure reliability, strengthening of structures, risk assessment, and decision analysis.

Driss Djaouad RAHAL. Professor at the Department of Civil Engineering at the Oran University of Sciences and Technology. Dr, new thesis PhD (INSA of Lyon, June 1990).

Research interests: studies of the risk zones (seismic, flood and landslide), artificial intelligence, expert systems, tools of decision-making aid, Geographical Information Systems (GIS), Computer-Aided Design (CAD), neurons network, transport systems and environment.

Farid RAHAL. Assistant Professor at the Department of Architecture at the Oran University of Sciences and Technology. His actual research interests include the modelisation of air quality, the emission cadastre of gazeous pollutants, urban risks and environnemental modelisation. 